\title{
Study on the Application of the Humanistic Spirit in the Teaching of College Writing Course
}

\author{
Li Dan \\ Humanities and Education College, Wuhan Guanggu Vocational College, Wuhan, Hubei, 430073
}

Keywords: University; practical teaching; humanistic spirit; penetration

\begin{abstract}
This paper is a certain degree of product application development to the humanistic spirit, practical writing has become the core curriculum of Humanities education. To strengthen the construction of humanistic spirit in Ideological and practical writing teaching is to adapt to the development of the results, this paper mainly discusses how to make humanistic spirit of university practical writing writing teaching. First, from the application of the internal and external and humanistic spirit in contact with are still emphasizes the effects of humanistic spirit of university practical writing writing teaching in view of the importance and the current problems in teaching, and finally puts forward the methods to solve the problems, to merge humanities spirit for university practical writing writing teaching process, improve students' spiritual civilization construction provide help for the related research.
\end{abstract}

\section{The connection between practical writing and humanistic spirit}

The application is a carrier for people to transmit information, transaction processing, communication, with the development of society, people living and working in more and more contacts, things become more and more complicated, the application of the function is also more and more, this paper not only has important practical application, the more a person is revealed between the lines the mode of thinking, culture and inherent virtue. The earliest application in Chinese Oracle Text period is the application of the application, can be said to Wen laid the cultural foundation China unified, in the continuous development of the river of time, the use of the application in people's daily in the development and progress of every little bit in all aspects, including the construction of humanistic spirit. Can be said that the application of the characteristics contained in the spirit of humanity, and for the people to write, write and write for the personnel, and for the purpose, which is fundamental to humanism; though not to give humanistic novel aesthetic pleasure, edify sentiment, but realistic and simple application of the content, chasing the source, the pursuit of true embodiment of humanistic spirit is not flashy. It can be said, also reflects the application of the function in the humanistic spirit, such as the promulgation of the rules in civil service, was released is that the standard and criterion, both have a tough side, side and humanistic care to protect the people's basic rights; the use of propaganda, in teaching work with the function of moral guidance, good to avoid evil, promoting people's moral standard and socialist concept of honor and disgrace with "Eight Honors and Eight Disgraces" as the main content of the concept of this article, the role of moral education can be said that the application is a prominent feature of the humanities; communication link and bridge role in communication, understanding can not trust the application of the carrier plays a coordinating role in the people, between people and people, the people and group, group and group, the humanistic spirit is also a kind of love [1].

\section{The lack of humanistic spirit in the teaching of practical writing and the importance of cultivating humanistic spirit}

Practical writing which plays an important role in the basic education, with the development of the times, practical writing teaching work has been steadily, its importance has not diminished but with the passage of time is more and more strong. But for a long time the teaching content, teaching means and teaching methods with no great breakthrough and innovation of the development of the 
times, which leads to the students on the course more or less resentment, stylized applied texts to make them feel boring, lack of humanistic spirit guide in the teaching, too much attention to the truth in the mechanical transmission, while the partial truth and to shape education guide does not attach importance to let this course in the hearts of the students more and more marginalized position, which should be interesting, conscious learning has gradually become to learn, not learn, to cultivate students' awareness of being ignored. In the humanities class university, construction of humanistic spirit, humanistic quality of the cultivation of the potential is like a raging fire when writing class did not learn from good experience and merit, will be more for their conduct in the spectator's attitude, to introduce the idea of humanistic concept consciousness, classroom the teaching is still in a state of mediocrity. In the teaching of practical writing training while theoretical knowledge and writing skills is important, but the application of education not only people's skills, should focus on the word "the" inherent truth and spirit, and to extend and expand [2].

This is the application of the party and government organs, social organizations, enterprises and institutions as well as personal affairs, in their daily work and learning in emotional communication, deal with the problem, and has a general style of the usual format, with the direct application of the practical value and strong function. It can be said is the application of functional paper has the most important value, so in the process of teaching practical writing course, this function is as the focus of the content of classroom, emphasizes the single tool in practical writing, and ignore other aspects into the teaching, a theory and function the way to make the classroom teaching more or less boring, students' interest weakened, on the application of the writing knowledge only stay in the one-sided tool level. From the long history of the practical writing, its own characteristics not only contain simple practicality and instrumentality, but also run through the specific history and culture of different periods in china. Practical writing is the carrier of recording the development of history and culture, and its own development and evolution is also a kind of culture. It has humanistic feelings and contains the traditional Chinese humanistic concept. At present, the cultural education and humanistic spirit in university practical writing writing teaching into work is very weak, universal tool in teaching system are one-sided emphasis on the application, ignoring the humanistic education, the importance of writing skills, despising quality education, lack of training and construction of students' humanistic spirit, this kind of education the way to cultivate qualified talents [3].

The application of the core curriculum curriculum belongs to the category of the writing of humanities education, it not only has practical skills such as life, occupation, and humanistic spirit, have embodied attributes of history and culture, will combine the teaching of humanistic spirit and writing, so that students can cultivate in writing knowledge learning, skill training and emotional attitude, the humanistic spirit and other aspects of the establishment of development balance, coordination, ability to adapt to the needs of the occupation in improving the students, for their own survival and development and sound personality can provide a strong backing. The university has long been the creation and dissemination place of various cultural fires in human society, and it also has the mission of cultivating humanistic spirit. The long tradition and history of the Chinese nation need to be inherited and extended here.

The university campus is also with the development of society in the times, it will inevitably suffer the negative impact of social transition period, such as utilitarianism, hedonism, money worship and so on, as a student of education and ideological cultivation places, university education has the students to establish a correct outlook on life and ethics of the mission, not corrupted by adverse external factor. The infiltration of humanistic spirit of practical writing teaching, is to cultivate students' independent thinking, and establish a sense of responsibility and mission fit, knowledge and truth church life, only a correct understanding of the thought, to distinguish between good and evil and is, do the pillars of society [4].

\section{The specific means to infiltrate humanistic spirit in the teaching of practical writing course in Universities}

If writing is simply to learn the theory and method of writing the ready-made templates available, 
so the students themselves through textbooks can be learned, the teacher's "teaching" is the need to instill some ideas and inspiration, consciousness and stimulate the enthusiasm of the students, the passive learning into active learning, let the students to look at this course from the historical and cultural point of view, the application of the writing of this course attitude. The first to introduce the concept is to make students aware of the practical writing learning in inheriting our traditional culture and history, the beginning of the ancient prose through the application of the records from the Oracle, described the social and life aspects to posterity, and as the splendid culture of Chinese classical works Confucianism left, writing and writing are inseparable. Thus, culture is not only exist in the arts, more throughout the daily life and behavior, since the birth of the moment, it has been imprinted with history and culture, the records of the culture and art of the country, it is also a kind of culture and history, first let students build up the awareness and consciousness, and to have a better learning effect. Second need to introduce the idea of teaching is to make students realize the importance of learning the practical writing is to create history and culture in the study, the application of the problem has been in the early ancient literati, the emperor will mind lofty ambition perfect equal Character Classic wisdom gentle played countless, as modern young people live in at present, especially countries should step up the pace of a man of tremendous promise, continuous learning and improvement, for the formation of contributing the modern way of life, and even influence range is very small, is also a kind of lofty sense of mission to be recognized successfully. Maybe it is an advertisement, perhaps is a notification, or a paragraph of text are likely to become the future history, let the future people understand today's documents, we may write today, is tomorrow's history, we create today, tomorrow is the culture. In the teaching of practical writing, these ideas should be set up not only to stimulate students' interest, but also to arouse students' enthusiasm and sense of responsibility in writing.

The practicality and instrumentality of practical writing often bring an illusion to people, that is, the article itself does not have aesthetic feeling, and even intentionally goes to its beauty in practical writing. And have human feelings and historical aspects of the beauty of the fact, the purpose of the application of explicit expression, how can the language, diction, expression is more direct and concise to the purpose of writing is an art. The writing of practical writing is aesthetic. In the process of teaching, we should pay attention to this aspect and cultivate students' cognition and understanding of aesthetic feeling. The specific teaching methods such as, should pay attention to the importance of emphasizing empathy between students of the subject and object of teaching of practical writing, subject and object, object, humanistic feelings, in the specific application, can be related to environmental protection, livelihood and other problems, can refer to ancient practical writing writing examples, such as "Jian Zhu Ke book" Li Si and the fate of Qin Keqing's future together, "before the model" in the description of a "gave the last" vivid "Ren an book" in the description allows us to see a long suffering and indomitable spirit, "offering twelve Lang Wen" in family description let a person see the unbearable, in modern times, is also held in Kang Youwei, and Hu Shi, Liang Qichao, Lu Xun, Mao Zedong and other famous great man left us Fan's work. All the good application with the humanistic spirit and feelings, not only make the full of emotion, emotion beyond, more concerned about history, culture, and concern for the fate of the country. In the present era of increasingly materialistic commodity economy, the construction of humanistic spirit is more important in the teaching of practical writing course should pay more attention to cultivating and improving the students' aesthetic consciousness, see writing contains higher and deeper level, cultivating the writing sense of responsibility and mission, with a positive the mental health and mental state in practical writing [5].

On the application of the contents of college writing teaching materials mainly for several modules, the paper documents, economic affairs, graduation thesis and cover paper, specific categories about dozens, the samples are suitable for students to learn the excellent classic. These articles have normative language, art and other aspects of the writing structure, express the correct view of things, the students' thoughts of dialectical materialism and the world view of the formation of the role, but also help to cultivate students' humanistic feelings, establish a serious work, for the attitude of the people. But these qualities are hidden in the book between the lines, the students 
really grasp the essence of it cannot do without the guidance of teachers, in the teaching of practical writing, teachers should fully tap the moral quality and will contain materials in this paper, we should pay more attention to the emotional aspects of humanity, philosophy and aesthetics the guide, broaden the extension of example contains the truth, firmly grasp the essence of the theory of ideology, which will be applied to students' writing training education, and different genres, according to infiltration to different writing subtle different characteristics, improve students' humanistic qualities in effect. 4 in the stage of practical writing, emphasis should be placed on the promotion of humanistic quality

In the application of conceptual stage, students first need to have a higher level of political theory in order to ensure the correctness of the article, from the perspective of theory and practice should be combined with teaching, teach students correct understanding of the policies of the party line, cultivating the students' consciousness of implementing consciousness; secondly, according to the practical writing has the characteristics of authenticity, consciously cultivate students the sense of responsibility, to ensure the authenticity is writing practical writing principles, cultivating students' pragmatic spirit, strong sense of responsibility, sense of responsibility in the form of learning; to cultivate students rigorous work style in terms of the application of the standard structure; finally, in the aspect of the application of language harmony requirements. Strengthen students' humanistic awareness, to cultivate students' language in legal and standardized terms under the premise of informed and humanization, to create a civilized and harmonious contemporary works with language full of humanistic care [6].

\section{Summary}

It can be said that the content of practical writing is mostly related to the themes of the state, nature, society and people's livelihood, and the humanistic spirit contained in it is naturally revealed and needs no special description. In the university practical writing writing teaching, humanistic spirit should also be the same as the natural infiltration of blood like to lecture, improve teaching achievements, cultivate students' interest in writing, improve the humanistic spirit in exercise skills at the same time.

\section{References}

[1] Zhang X, Yang M. Study on integrating the concept of China Dream in medical humanistic spirit[J]. China Medical Education Technology, 2014.

[2] Jianrong L I. On the Humanistic Mission of Creative Writing Teaching Reform in Universities[J]. Journal of Guangxi Science \& Technology Normal University, 2017.

[3] Jianrong L I. On the Humanistic Mission of Creative Writing Teaching Reform in Universities[J]. Journal of Guangxi Science \& Technology Normal University, 2017.

[4] Yuan T, Bin Y I, Mao L, et al. A Study on the Application of SPICE in the Teaching of the Course of Circuit Principles[J]. Journal of Chongqing Electric Power College, 2016.

[5] Yuan T, Bin Y I, Mao L, et al. A Study on the Application of SPICE in the Teaching of the Course of Circuit Principles[J]. Journal of Chongqing Electric Power College, 2016.

[6] Gao Y Y, Vocationalamp J. A Study on the Cultivation of Students' Humanistic Literacy in the Teaching of Chinese in Vocational Colleges[J]. Journal of Chongqing Electric Power College, 2015.

Introduction of the author: Li Dan. female, Hubei province, September 12th, 1982. Master Degree Candidate, lecturer, General education and Public Administration. 